\title{
Cysteine and glutathione concentrations in plasma and bronchoalveolar lavage fluid after treatment with $N$-acetylcysteine
}

\author{
Myrtle M E Bridgeman, Mark Marsden, William MacNee, David C Flenley, \\ Andrew P Ryle
}

\begin{abstract}
$N$-acetylcysteine (600 $\mathrm{mg} /$ day) was given to patients by mouth for five days before bronchoscopy and bronchoalveolar lavage to determine whether $\boldsymbol{N}$-acetylcysteine could increase the concentrations of the antioxidant reduced glutathione in plasma and bronchoalveolar lavage fluid. Bronchoalveolar lavage was performed 1-3 hours (group $2, n=9$ ) and 16-20 hours (group $3, n=10$ ) after the last dose of $\boldsymbol{N}$-acetylcysteine and the values were compared with those in a control group receiving no $\boldsymbol{N}$-acetylcysteine (group $1, n=8$ ). $N$-acetylcysteine was not detected in plasma or lavage fluid. Plasma concentrations of cysteine, the main metabolite of $N$ acetylcysteine and a precursor of reduced glutathione, were greater in the groups receiving treatment (groups 2 and 3 ) than in group 1 . Cysteine concentrations in lavage fluid were similar in the three groups. Concentrations of reduced glutathione were greater in both plasma and lavage fluid in group 2 than in group 1. These data suggest that $N$ acetylcysteine given by mouth is rapidly deacetylated to cysteine, with resulting increases in the concentrations of cysteine in plasma and of reduced glutathione in plasma and the airways, which thus temporarily increase the antioxidant capacity of the lung.
\end{abstract}

An imbalance may occur in the distal airspaces of the lung between oxidants and antioxidants and may have a role in the pathogenesis of emphysema. ${ }^{12}$ Oxidants, produced by inflammatory cells during endogenous metabolism, xenobiotic insult, or both, may cause degradation of lung connective tissue ${ }^{1}$ and inactivate antiproteases. ${ }^{34}$ Enhancement of the antioxidant capacity of both blood and the distal airspaces may therefore prevent oxidative damage to the lung, though the role of an oxidant-antioxidant imbalance in the pathogenesis of lung injury remains to be proved. ${ }^{5}$

During the past 20 years the antioxidant $N$ acetylcysteine has been used to treat patients with chronic obstructive pulmonary disease. ${ }^{6}$ Long term oral administration of $\mathrm{N}$-acetylcysteine reduces the number of acute exacerbations in patients with chronic obstructive disease,${ }^{78}$ though the mechanism underlying this effect remains unclear. $N$-acetylcysteine protects lung epithelial cells in vitro against oxidant injury mediated by polymorphonuclear leucocytes ${ }^{9}$ and dogs against pulmonary oxygen toxicity in vivo. ${ }^{10}$ Thus $N$ acetylcysteine has antioxidant potential and its main metabolite, cysteine, a precursor in the biosynthesis of reduced glutathione, is an extremely important intracellular and extracellular antioxidant. ${ }^{1112}$

The aim of this study was to determine if $N$-acetylcysteine given by mouth could increase the concentrations of the antioxidants cysteine and reduced gluytathione in plasma and in bronchoalveolar lavage fluid in man.

\section{Methods}

All patients were undergoing routine diagnostic bronchoscopy for the investigation of a lung tumour. Three groups of patients were studied. Group $1(n=10)$ acted as a control group and received no $N$-acetylcysteine. Groups 2 and 3 (both $\mathrm{n}=12$ ) received $N$-acetylcysteine in a single daily dose of $600 \mathrm{mg}$ for five days. Bronchoalveolar lavage was performed either 1-3 hours (group 2) or 16-20 hours (group 3) after the last dose of $N$-acetylcysteine. The patients were randomly assigned to the groups. One patient in each group had chronic obstructive pulmonary disease and none had pulmonary fibrosis. Informed consent was given by all the patients and permission was obtained from our local ethics committee.

\section{SAMPLES}

Plasma and bronchoalveolar lavage samples were obtained from three groups of patients: group 1 ( $\mathrm{n}=8$, six male; mean age 70 (range 3577) years), consisting of three smokers, three ex-smokers, and two non-smokers; group 2 $(n=9$, eight male; mean age 65 (range 48-73) years), consisting of six smokers, and three ex-smokers; group 3 ( $\mathrm{n}=10$, eight male; mean age 59 (range 31-71) years), consisting of two smokers, six ex-smokers, and two nonsmokers.

\section{Bronchoalveolar lavage fluid}

Fibreoptic bronchoscopy was performed under local anaesthesia ( $2 \%$ topical lignocaine) after premedication with diamorphine and atropine. The bronchoscope was wedged in a segmental bronchus in the lung contralateral to the tumour and $30 \mathrm{ml}$ aliquots of warmed sterile saline (to a total volume of $240 \mathrm{ml}$ ) were instilled and recovered. The volumes instilled and returned were recorded. Lavage fluid was immediately filtered through four sterile gauze 
swabs and then centrifuged at $4^{\circ} \mathrm{C}$ for 10 minutes at $150 \mathrm{~g}$ to remove cells. The supernatant was removed and centrifuged again at $4^{\circ} \mathrm{C}$ for 10 minutes at $1400 \mathrm{~g}$, to produce completely cell free fluid.

\section{Blood samples}

Venous blood samples $(5 \mathrm{ml})$ were drawn into lithium heparin at the time of bronchoalveolar lavage and centrifuged at $4^{\circ} \mathrm{C}$ for 10 minutes at $800 \mathrm{~g}$ to obtain plasma.

\section{ASSAYS}

\section{Thiol determinations}

Concentrations of cysteine, reduced glutathione and free $N$-acetylcysteine were measured. ${ }^{13}$ Immediately after centrifugation the sample of plasma or lavage fluid $(100 \mu \mathrm{l})$ was mixed with $8 \mathrm{mM}$ monobromobimane (Thiolyte, Calbiochem) in $50 \mathrm{mM} \mathrm{N}$-ethylmorpholine, $\mathrm{pH} 8.0(100 \mu \mathrm{l})$, and phosphate buffered saline, $\mathrm{pH} \quad 7 \cdot 4 \quad\left(\begin{array}{ll}10 & \mu \mathrm{l}\end{array}\right)$. Monobromobimane is relatively insoluble in aqueous solutions and was predissolved in a small amount of acetonitrile. The sample was stored in the dark at room temperature for five minutes and then acidified to stop the reaction by the addition of $100 \%(w / v)$ trichloroacetic acid. The precipitated protein was removed by centrifugation for 10 minutes with a microfuge (Microcentaur, MSE) at high speed. Aliquots of the supernatants $(100 \mu \mathrm{l})$ were applied to a high pressure liquid chromatography column.

\section{Chromatography}

The chromatographic separation of the thiolmonobromobimane derivatives was achieved using a Waters (Milford, Massachusetts) Nova-Pak steel column $(3.9 \times 150 \mathrm{~mm})$ packed with $4 \mu \mathrm{m}$ octadodecyl silica reversed phase material. The analytical column was protected by a small Waters Guard-Pak precolumn packed with the same material. The chromatographic system consisted of two Model 410 pumps, an automated gradient controller, a Waters intelligent sampler processor model 710 (automatic injection system), and a data module (M730) for peak integration. A fluorescence detector, model 420 , was used for peak detection (all from Waters).

Percentage recovery and albumin concentrations of bronchoalveolar lavage fluid cysteine and reduced glutathione concentrations in plasma and lavage fluid, and lavage fluid: plasma cysteine and glutathione ratios in three groups of patients (mean (SEM) values)

\begin{tabular}{|c|c|c|c|}
\hline & Group 1 & Group 2 & Group 3 \\
\hline $\begin{array}{l}\% \text { recovery of lavage fluid } \\
\text { Lavage fluid albumin }(\mathrm{mg} / \mathrm{l})\end{array}$ & $\begin{array}{l}59 \cdot 0(3 \cdot 3) \\
27 \cdot 3(5 \cdot 0)\end{array}$ & $\begin{array}{l}51 \cdot 1(4 \cdot 0) \\
28 \cdot 5(5 \cdot 2)\end{array}$ & $\begin{array}{l}48 \cdot 9(7 \cdot 1) \\
24 \cdot 2(2 \cdot 8)\end{array}$ \\
\hline $\begin{array}{l}\text { CYSTEINE } \\
\text { In lavage fluid }(\mu \mathrm{mol} / \mathrm{l})\end{array}$ & $0 \cdot 1(0 \cdot 1)^{\star}$ & $0.3(0 \cdot 1)^{\star}$ & $\begin{array}{c}0 \cdot 1 \\
(0 \cdot 1)^{\star}\end{array}$ \\
\hline $\begin{array}{l}\text { In plasma ( } \mu \mathrm{mol} / \mathrm{l}) \\
\text { Lavage fluid: plasma ratio }\end{array}$ & $\begin{array}{l}3.5(0 \cdot 3) \\
0.04\end{array}$ & $\begin{array}{l}8 \cdot 1(1 \cdot 0) \\
0 \cdot 04\end{array}$ & $\begin{array}{l}5 \cdot 3(0 \cdot 5) \\
0.02\end{array}$ \\
\hline $\begin{array}{l}\text { REDUCED GLUTATHIONE (GSH) } \\
\text { In lavage fluid }(\mu \mathrm{mol} / \mathrm{l}) \\
\text { In plasma GSH }(\mu \mathrm{mol} / \mathrm{l}) \\
\text { Lavage fluid: plasma ratio }\end{array}$ & $\begin{array}{l}2.1(0.5) \\
1.7(0.3) \\
1.24\end{array}$ & $\begin{array}{l}5.9(0.7)^{\star} \\
3.5(0.8) \\
1.69\end{array}$ & $\begin{array}{l}2.6(0.5) \\
2.9(0.8) \\
0.90\end{array}$ \\
\hline
\end{tabular}

${ }^{\star} p<0.05$ when lavage fluid concentrations are compared with those of plasma.
The elution solvent A was $8.5 \%(\mathrm{v} / \mathrm{v})$ acetonitrile, $0.25 \%(\mathrm{v} / \mathrm{v})$ acetic acid, and $0.25 \%$ $(\mathrm{v} / \mathrm{v})$ perchloric acid, $\mathrm{pH} 3.65$; and solvent $\mathrm{B}$ was $75 \%(v / v)$ acetonitrile in distilled water. Isocractic conditions $(100 \% \mathrm{~A})$ were maintained for 14 minutes, then changed to $100 \% \mathrm{~B}$ for 10 minutes and thereafter immediately returned to $100 \% \mathrm{~A}$ for re-equilibration for six minutes. The flow rate was maintained at $1 \mathrm{ml} /$ $\min$.

Standard solutions of cysteine, reduced glutathione, and $\mathrm{N}$-acetylcysteine were prepared daily with phosphate buffered saline $(\mathrm{pH}$ $7 \cdot 4$ ) in the same way as the test solutions. The limit of the detection was $5 \mathrm{pmol}$ on column. The coefficient of variation of the assay was $5 \%$ for repeated analyses of standard solutions ( $\mathrm{n}$ $=20$ ).

\section{Other assays}

Albumin and $\alpha_{1}$-proteinase inhibitor concentrations were determined with an enzyme linked immunosorbent assay (ELISA) with unconjugated (Cappel Laboratories, Dynatech) and peroxidase conjugated (Dakopatts) antisera to human albumin and $\alpha_{1}$-proteinase inhibitor. ${ }^{14}$ The coefficient of variation for both assays was $5 \%$. Catalase activity was determined spectrophotometrically. ${ }^{15-17}$ Tests for haemolysis were performed on plasma samples with diagnostics kit No 525 (Sigma). Lactate dehydrogenase activity was determined by an ultraviolet kit method (BoehringerMannheim).

\section{Statistics}

Analyses were performed on duplicates and mean values were obtained. Mean values of different groups were compared by the non-parametric Wilcoxon rank sum test for unpaired data.

\section{Results}

$\mathrm{N}$-acetylcysteine was not detected in plasma or lavage fluid.

\section{PLASMA FINDINGS}

Plasma cysteine concentrations were higher in groups 2 and 3 than in control patients ( $\mathrm{p}<0.05$ : table). Reduced glutathione concentrations differed significantly only between group 2 and group 1 (table).

\section{LAVAGE FLUID FINDINGS}

Because of the uncertain, and probably variable, dilution of the epithelial lining fluid that occurs during bronchoalveolar lavage, concentrations of the thiols in lavage fluid were also expressed in relation to albumin concentrations. Cysteine:albumin ratios in bronchoalveolar lavage fluid did not differ significantly from those of the control group in either group 2 or group 3, though they tended to be higher in group 2 (fig 1). Reduced glutathione concentrations in lavage fluid, when corrected for albumin, were higher in group 2 (lavage performed 1-3 hours after the last dose of $N$-acetylcysteine) than in the control group $(\mathrm{p}<0.05)$ but not in group 3 (fig 2). The increase in 
Figure 1 Cysteine concentrations (means with SEM) with respect to albumin in the bronchoalveolar lavage fluid of three groups of patients: group 1 is the control ( no Nacetylcysteine (NAC)); $N$-acetylcysteine was given by mouth $(600 \mathrm{mg} /$ day for five days) to groups 2 and 3 and samples were obtained 1-3 hours (group 2) and 16-20 hours (group 3) after the last dose of $N$-acetylcysteine.

Figure 2 Reduced glutathione concentrations (means with SEM) with respect to albumin in the bronchoalveolar lavage fluid of three groups of patients (see fig 1).
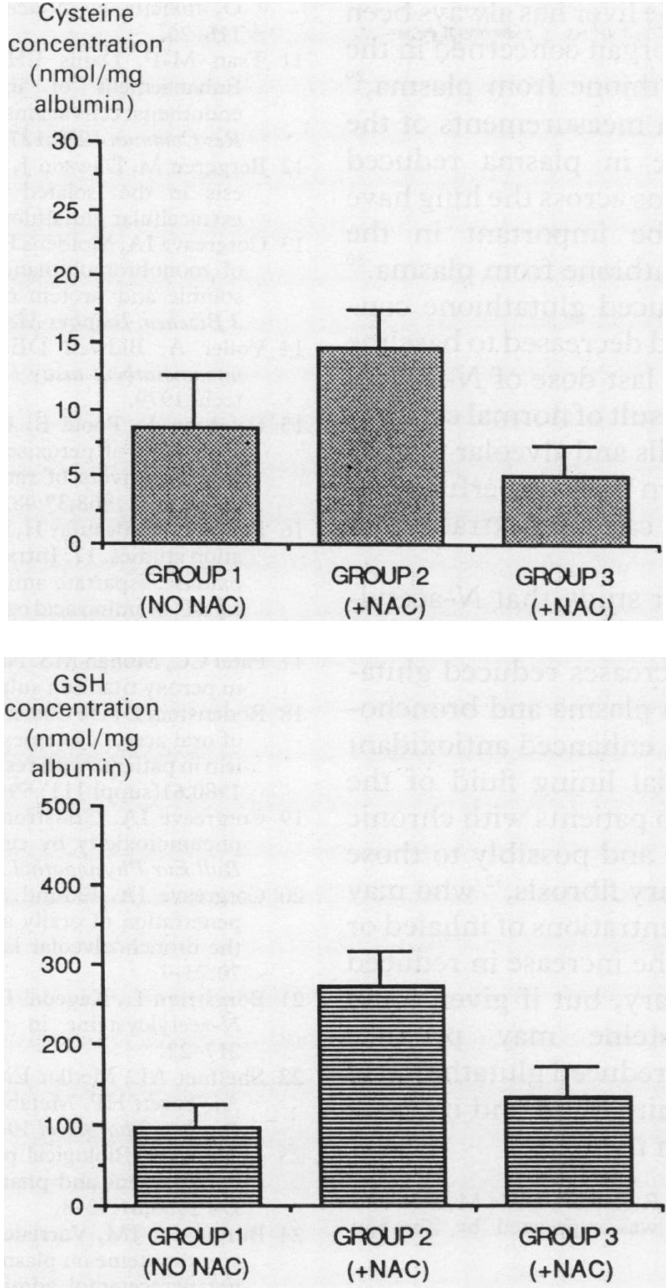

reduced glutathione in group 2 was not due to differences in the proportion of lavage fluid recovered or of albumin concentrations in lavage fluid between the three groups (table). When thiol concentrations in lavage fluid, unrelated to albumin and plasma, were compared (table) cysteine concentrations in lavage fluid were lower than plasma cysteine concentrations in all three groups $(p<0.05)$, whereas reduced glutathione concentrations in lavage fluid and plasma did not differ significantly between groups.

No lactate dehydrogenase activity was detected in bronchoalveolar lavage fluid. Any samples of bronchoalveolar lavage fluid containing red cells were not included in the study. The concentrations of albumin and $\alpha_{1}$ proteinase inhibitor and the activities of catalase in serum and bronchoalveolar lavage fluid (data not shown) did not differ significantly between the three groups.

\section{Discussion}

After an oral dose of ${ }^{35} \mathrm{~S}$ labelled $\mathrm{N}$-acetylcysteine radioactivity can be detected in human lung tissue and bronchial secretions, ${ }^{18}$ showing that after oral administration of $N$-acetylcysteine products of its metabolism enter lung tissue and lung lining fluid. In this study $N$ acetylcysteine was not detected in plasma or in bronchoalveolar lavage fluid of patients who had taken $\mathrm{N}$-acetylcysteine. This is in agree- ment with evidence that $N$-acetylcysteine is deacetylated and metabolised when administered orally and does not penetrate the epithelial lining fluid. ${ }^{1920}$ This deacetylation of $\mathrm{N}$-acetylcysteine probably occurs in the liver and the gut, ${ }^{21-23}$ and it resulted in significantly increased plasma cysteine concentrations, an observation that has been made by other workers. ${ }^{192324}$

Cysteine is a precursor in the biosynthesis of glutathione and hence an increase in plasma cysteine would be expected to be followed by an increase in plasma glutathione concentrations. In this study plasma reduced glutathione concentrations (table) did increase significantly in patients who had taken $N$-acetylcysteine, though this increase was short lived and was not present 20 hours after the last dose of $N$ acetylcysteine. The transience of the increase is presumably due to its rapid removal from plasma by the kidney or by feedback inhibition of $\gamma$-glutamylcysteine synthetase by glutathione, ${ }^{25}$ or to both mechanisms.

In lavage fluid the position was reversed; cysteine concentrations did not increase significantly after $\mathrm{N}$-acetylcysteine administration, whereas reduced glutathione concentrations in lavage fluid were higher in those patients who had received $N$-acetylcysteine up to three hours before lavage. This increase was short lived and was not present 20 hours after the last dose of $N$-acetylcysteine. As lactate dehydrogenase was not detected in lavage fluid, cell lysis did not account for the increase in reduced glutathione found there, nor did the presence of red cells, because samples contaminated with red cells were discarded. There are therefore three possible sources of reduced glutathione found in lavage fluid: airway and alveolar epithelial cells, alveolar macrophages, or transudation from blood.

Recent studies show that reduced glutathione is present in high concentrations in the epithelial lining fluid of both $\operatorname{man}^{26}$ and the rat. ${ }^{27}$ The question arises of how $N$-acetylcysteine increases concentrations of reduced glutathione in lavage fluid. Equilibration of cysteine and reduced glutathione in plasma and lavage fluid is unlikely to occur because cysteine concentrations in lavage fluid are almost 100 times lower than plasma cysteine concentrations and reduced glutathione concentrations in lavage fluid are higher than plasma reduced glutathione concentrations in group 2 . If we take into account the dilution factor due to the instillation of saline during lavage, the true concentrations of reduced glutathione and cysteine in the epithelial lining fluid may be in fact much greater than those in plasma-by a factor of at least $200 .{ }^{26}$ Kelly $e t a l^{28}$ have stated that the concentration of epithelial lining fluid is about $2 \%$ of the bronchoalveolar lavage fluid and so equilibration between plasma and lavage fluid may have occurred, particularly for cysteine.

The increase in reduced glutathione in lavage fluid after administration of $N$-acetylcysteine may result from active secretion by lung epithelial cells or alveolar macrophages (or both) or from active transfer from the blood to 
the alveolar air space. The liver has always been thought to be the major organ concerned in the uptake of reduced glutathione from plasma, ${ }^{29}$ but in the mouse at least measurements of the arteriovenous difference in plasma reduced glutathione concentrations across the lung have shown this organ to be important in the removal of reduced glutathione from plasma. ${ }^{30}$ In our experiments reduced glutathione concentrations in lavage fluid decreased to baseline levels 20 hours after the last dose of $N$-acetylcysteine, probably as a result of normal catabolism by lung epithelial cells and alveolar macrophages, as it is well known that the perfused rat lung and isolated cells can use extracellular reduced glutathione. ${ }^{12} 31$

We conclude from our study that $N$-acetylcysteine, given in a single $600 \mathrm{mg}$ daily dose for five days, transiently increases reduced glutathione concentrations in plasma and bronchoalveolar lavage fluid. An enhanced antioxidant potential in the epithelial lining fluid of the lung may be beneficial to patients with chronic obstructive lung disease and possibly to those with idiopathic pulmonary fibrosis, ${ }^{32}$ who may be exposed to high concentrations of inhaled or endogenous oxidants. The increase in reduced glutathione was temporary, but if given more frequently $N$-acetylcysteine may produce longer term increases in reduced glutathione in plasma and epithelial lining fluid and increase antioxidant protection in the lung.

Our thanks go to Dr C Selby, Dr R Sankaran, Ms M Bain, and Dr J-M Sallenave. The work was supported by Zambon Pharmaceutici, Milan, Italy.

1 Riley DJ, Kerr JS. Oxidant injury of the extracellular matrix-potential role in the pathogenesis of pulmonary emphysema. Lung 1985;163:1-13.

2 Flenley DC, Downing I, Greening AP. The pathogenesis of emphysema. Bull Eur Physiopathol Respir 1986;22: 2455-525.

3 Johnson D, Travis J. The oxidative inactivation of human $x_{1}$-proteinase inhibitor. $J$ Biol Chem 1979;254:4022-6.

4 Kramps JA, Twisk Ch van, Klasen EC, Dijkman JH. Interactions among polymorphonuclear leucocytes released elastase and bronchial antileucoprotease. Clin Sci 1988;74:53-62.

5 Heffner JE, Repine JE. Pulmonary strategies of antioxidant defence. Am Rev Respir Dis 1989;140:513-24.

6 Ziment I. Acetylcysteine: a drug with an interesting past and a fascinating future. Respiration 1986;50:26-30.

7 Bowman R, Backer U, Larsson S, Melander B, Wahlander L. Oral acetylcysteine reduces exacerbation rate in chronic bronchitis. Eur J Respir Dis 1983;64:405-15.

8 Rasmussen JB, Glennow C. Reduction in days of illness after long term treatment with $\mathrm{N}$-acetylcysteine controlledrelease tablets in patients with chronic bronchitis. Eur $J$ Respir Dis 1988;1:351-5.

9 Simon LM, Suttorp N. Lung cell oxidant injury: decrease in oxidant mediated cytotoxicity by $N$-acetylcysteine. Eur $J$ Respir Dis 1985;66(suppl 139):132-5.

10 Wagner PD, Mathieu-Costello O, Bebout DE, Gray AT, Natterson $P D$, Glennow C. Protection against pulmonary
$\mathrm{O}_{2}$ toxicity by $\mathrm{N}$-acetylcysteine. Eur Respir $J$ 1989;2: 116-26.

11 Tsan M-F, Danis EH, Del Vecchio PJ, Rosano CL Enhancement of intracellular glutathione protects endothelial cells against oxidant damage. Biochem Biophys Res Commun 1985;127:270-6.

12 Berggren M, Dawson J, Moldeus P. Glutathione biosynthesis in the isolated perfused rat lung: utilisation of extracellular glutathione. FEBS Lett 1984;176:189-92.

13 Cotgreave IA, Moldeus P. Methodologies for the application of monobromobimane to the simultaneous analysis of soluble and protein components of biological systems. J Biochem Biophys Meths 1986;13:231-49.

14 Voller A, Bidwell DE, Bartlett A. The enzyme linked immunosorbent assay (ELISA). Vol 1. Guernsey: Dynatech, 1979.

15 Leighton F, Poole B, Beaufay $\mathrm{H}$, et al. The large-scale separation of peroxisomes, mitochondria and lysosomes from the livers of rats injected with Triton WR-1339. J Cell Biol 1968;37:482-13.

16 Baudhuin P, Beaufay H, Ralman-Li Y, et al. Tissue fractionation studies. 17. Intracellular distribution of monoamine oxidase, aspartate aminotransferase, alanine aminotransferase, $D$-amino acid oxidase and catalase in rat liver tissue Biochem J 1964;92:179-84.

17 Patel CC, Mohan MS. Nature of the colour-forming species in peroxy titanium sulphate. Nature 1960;186:803-4.

18 Rodenstein D, De Coster A, Gazziniga A. Pharmacokinetic of oral acetyl cysteine: absorption, binding and metabolism in patients with respiratory disorders. Eur J Respir Dis 1980;61(suppl 111):59-60.

19 Cotgreave IA, Grafstrom RC, Moldeus P. Modulation of pneumotoxicity by cellular glutathione and precursors. Bull Eur Physiopathol Respir 1986;22:263s-66s.

20 Cotgreave IA, Eklund A, Larsson K, Moldeus PW. No penetration of orally administered $\mathrm{N}$-acetylcysteine into the bronchoalveolar lavage fluid. Eur J Respir Dis 1987; 70:73-7.

21 Borgstrom L, Kagedal B, Paulsen O. Pharmacokinetics of $N$-acetylcysteine in man. Eur $J$ Pharmacol 1986;31 217-22.

22 Sheffner AL, Medler EM, Bailey KR, Gallo DG, Mueller AJ, Sarett HP. Metabolic studies with $N$-acetylcysteine. Biochem Pharmacol 1966;15:1523-35.

23 Maddock J. Biological properties of acetyl cysteine-assay development and pharmacokinetic studies. Eur $J$ Respir Dis 1980;61:52-8.

24 Burgunder JM, Varriale A, Lauterburg BH. Effect of $N$ acetylcysteine on plasma cysteine and glutathione following paracetamol administration. Eur J Clin Pharmaco 1989;36:127-31.

25 Richman PG, Meister A. Regulation of $\gamma$-glutamyl cystein synthetase by non-allosteric inhibition by glutathione. $J$ Biol Chem 1975;250:1422-6.

26 Cantin AM, North SL, Hubbard RC, Crystal RG. Norma alveolar epithelial lining fluid contains high levels of glutathione. J Appl Physiol 1987;63:152-7.

27 Jenkinson SG, Black RD, Lawrence RA. Glutathione concentrations in rat lung bronchoalveolar lavage fluid: effects of hyperoxia. $J$ Lab Clin Med 1988;112:345-51.

28 Kelly CA, Fenwick JD, Corris PA, Fleetwood A, Hendrick DJ, Walters EH. Fluid dynamics during bronchoalveola lavage. Am Rev Respir Dis 1988;138:81-4.

29 Anderson ME, Bridges RJ, Meister A. Direct evidence for inter-organ transport of glutathione and that the nonfiltration renal mechanism for glutathione utilisation involves $\gamma$ glutamyl transpeptidase. Biochem Res Commun involves $\gamma$ glutam

30 Martensson J, Jain A, Frayer W, Meister A. Glutathione metabolism in the lung: inhibition of its synthesis leads to lamellar body and mitochondrial defects. Proc Natl Acad Sci USA 1989;86:5296-300.

31 Dawson JR, Vahakangas $\mathrm{K}$, Jernstrom $\mathrm{B}$, Moldeus $\mathrm{P}$. Glutathione conjugation by isolated lung cells and the isolated perfused lung. Eur J Biochem 1984;138:439-43.

32 Cantin AM, Hubbard RC, Crystal RG. Glutathione deficiency in the epithelial lining fluid of the lower respiratory tract in idiopathic pulmonary fibrosis. $\mathrm{Am} \mathrm{Rev}$ Respir Dis 1989;139:370-2. 